\title{
Long Noncoding RNAs in Interaction With RNA Binding Proteins in Hepatocellular Carcinoma
}

\author{
Ashraf Mohamadkhani ${ }^{1, "}$ \\ ${ }^{1}$ Liver and Pancreatobiliary Disease Research Center, Digestive Disease Research institute, Shartati Hospital, Tehran University of Medical Sciences, Tehran, IR Iran \\ ${ }^{*}$ Corresponding Author: Ashraf Mohamadkhani, Liver and Pancreatobiliary Disease Research Center, Digestive Disease Research institute, Shartati Hospital, Tehran University of \\ Medical Sciences, North Kargar Ave. Tehran, IR Iran. Tel: +98-2182415227, Fax: +98-2182415400, E-mail: ashraf@ams.ac.ir, mohamadkhani.ashraf@gmail.com \\ Received: March 6, 2014; Accepted: March 7, 2014
}

\begin{abstract}
Background: Gene expression microarrays' analyses provide a description of long noncoding RNAs(lncRNAs) with lack of coding protein function that is often important in human cancer.

Objectives: A number of IncRNAs that have been well characterized in hepatocellular carcinoma (HCC) have been scheduled in this study to discuss for protein-lncRNA interaction.

Materials and Methods: The identified IncRNAs were analyzed by bioinformatics tools, starBase and lncRNA db, to anticipate the RNAbinding proteins (RBPs) that tend to interact to HCC-related lncRNAs. The most important predicted RBPs in interaction with well-known IncRNAs in HCC were briefly discussed.

Results: The lncRNAs HOTTIP, H19, HOTAIR, MALAT1, antisense Igf2r (AIR), HOXA13, GTL2 (also called MEG3) and uc002mb have been reported in association with HCC. Besides, this study predicted that eIF4AIII, PTB and FUS were the most involved RBPs in interaction with HCC-related IncRNAs.

Conclusions: This information provides an explanation for the previously valuable literature on the functions of lncRNAs and suggest for the novel therapeutic targeting.
\end{abstract}

Keywords:Carcinoma, Hepatocellular; Long Noncoding RNA; RNA-Binding Proteins

\section{Background}

Progresses in whole genome expression profiling and transcriptome sequencing have been revealed new type of RNAs and their specific functions in eukaryotic cells (1). Long non-coding RNAs (lncRNAs) comprise the mainstream of transcripts that are larger than 200 nucleotides (nt) and not translated into proteins. Application of next generation sequencing and high-resolution of microarray techniques discovered more than 14,000 IncRNA transcripts in five classes of sense, antisense, bidirectional, intronic, and intergenic (2). The majority of mammalian coding genes have complementary noncoding antisense transcription (3). Many of which that are implicated in a cis-acting performance, mediate the modifications of native chromatin and the expression of neighboring genes in gene silencing way (3). Conformational changes in essential domains of lncRNAs will capable them to interact to the complementary base pair of other RNAs as well as proteins and perhaps DNA. Alternative splicing of RNAs are responsible for constructing domains in IncRNAs structures $(1,4)$. Recently, many novel approaches have been developed to identify the functional role of IncRNAs molecules in the development of human diseases. These molecules regulate many biological processes such as epigenetic modulators that potentially alter the levels of mRNA transcripts in human cancer (5). Application of lncRNAs as cancer diagnostic or prognostic biomarkers has been reported in several studies (6). For example, PCA3, a well-known prostate-specific IncRNA, is markedly overexpressed in prostate cancer and has been offered as cancer diagnostic biomarker (4). Previous studies also showed that patients with higher IncRNAs expression had poorer prognosis in liver cancer (7). Expression of highly upregulated in liver cancer (HULC) lncRNA in plasma has been known as a novel mRNA-like lncRNA biomarker for the diagnosis of HCC (8).

Recent study showed that IncRNAs are associated with cancer subtypes or may have a tumor-promoting or suppressing function (5). Genetic studies have proved that a significant number of non-coding RNAs (ncRNAs) are associated with hepatocellular carcinoma (HCC) as the most common types of cancer in areas where chronic viral hepatitis are prevalent (9). Essentially, lncRNAs are involved in the pathogenesis of HCC through regulation of carcinoma-related signaling pathways such as MAPK signaling 
pathway (10). The etiology and the overwhelming majority of HCC cases are associated with a chronic inflammatory process in viral hepatitis. Both hepatitis B virus (HBV) DNA and HCV RNA could change the cellular regulatory mechanisms and leading to HCC $(11,12)$. It has been found that chromosomal instability, cellular gene expression alteration and in particular the transactivating genes by HBx are important reasons in pathogenesis of HBV-associated HCC $(13,14)$. Generally, there are specific motifs within the binding sites of lncRNAs for protein regulatory factors $(15,16)$. Comprehensive RNA-binding proteins (RBP) dataset from various cell types have been provided by high-throughput CLIP-Seq technology. Additionally, several computational approaches have been developed to recognize lncRNAsproteins interactions and help to find out the regulatory mechanisms in human cancer $(17,18)$. These methods highlight the potential uses of ncRNAs in early detection, diagnosis and therapy of cancers such as HCC.

\section{Objectives}

In this study HCC-related IncRNAs were extracted from literature to evaluate their possible interactions with RBPs by performing computational programs. Prediction of lncRNAs-RBPs interactions will be potentially useful to explore the molecular mechanisms that are regulated by lncRNAs and influence on the function of proteins in HCC.

\section{Materials and Methods}

\subsection{Search Strategy and Selection of Long non-Cod- ing RNAs (LncRNAs)}

PubMed and reference lists of relevant review articles were searched to retrieve HCC-related IncRNAs. All searches were updated in December 2013. Searching re- sults were listed in Table 1 ; as shown, most of lncRNAs are overexpressed, which indicates an oncogenes-like role of lncRNAs in cancer biology.

\subsection{Prediction of RBP Binding Sites on LncRNA Target}

StarBase v 2.0 (http://starbase.sysu.edu.cn/) has distinctive features and improved as Database, Visualizer, and Analyzer. This server was used to discover the IncRNAsRBPs interactions. Included lncRNAs from published studies was administered to identify the possible RBP binding sites among them.

\subsection{RNA-Binding Protein (RBP) Function Information}

StarBase has provided promising information of predicted RBPs for each lncRNA target. This server provides functional insights on target sites within RBP-lncRNA interaction, shows the target location on chromosomes and the number of transcripts by Ensembl ID. LncRNAdb (http://www.lncrnadb.org/) is a valuable database to provide information of annotated lncRNAs including sequences, structural information, genomic context, expression, subcellular localization, conservation and functional evidence. The summarized information of lncRNAs and related RBPs were indicated in Table 2.

\section{Results}

Experimental data showed the achievement of lncRNAs in regulation of gene expression and most often, they are poor prognostic biomarker in patients with hepatocellular carcinoma (HCC) $(8,25,26)$. IncRNA expression is

\begin{tabular}{|c|c|c|c|}
\hline LncRNAs & Gene Description & Functional Annotation & Reference \\
\hline HOTTIP & $\begin{array}{l}\text { HOXA is bidirectional transcript with HOXA13 } \\
\text { (Homeobox protein Hox-A13) }\end{array}$ & Controls activation of several 5' HOXA genes & $(7,10)$ \\
\hline H19 & $\begin{array}{c}\text { Imprinted maternally expressed transcript at } \\
\text { the Igf2 locus }\end{array}$ & $\begin{array}{l}\text { Possibly will act as a tumor suppressor, influ- } \\
\text { ences growth via control of Igf2 expression. }\end{array}$ & $(19-24)$ \\
\hline HOTAIR & $\begin{array}{l}\text { Hox antisense intergenic RNA, that is co-ex- } \\
\text { pressed with HOXC genes. }\end{array}$ & $\begin{array}{l}\text { HOTAIR acts as a scaffold for protein com- } \\
\text { plexes. Involve in chromatin modifications. }\end{array}$ & $(25-27)$ \\
\hline HULC & $\begin{array}{l}\text { Highly Up-regulated in Liver Cancer, } 500 \text { bp in } \\
\text { two exon polyadenylated transcript }\end{array}$ & $\begin{array}{l}\text { Complicated in HBx-mediated hepatocar- } \\
\text { cinogenesis, downregulates the expression of } \\
\text { some microRNAs, including miR-372 }\end{array}$ & $(28)$ \\
\hline MALAT1 & $\begin{array}{c}\text { Metastasis-associated lung adenocarcinoma } \\
\text { transcript } 1\end{array}$ & $\begin{array}{c}\text { Highly conserved transcript that regulates } \\
\text { the expression of metastasis-associated } \\
\text { genes }\end{array}$ & $(10,29)$ \\
\hline antisense Igf2r (AIR) & $\begin{array}{l}\text { Transcribed from an antisense promoter } \\
\text { located in intron } 2 \text { of the Igf } 2 \text { r (insulin-like } \\
\text { growth-factor type- } 2 \text { receptor) gene }\end{array}$ & $\begin{array}{l}\text { Regulates genomic imprinting of a cluster of } \\
\text { autosomal genes (Igf2r, Slc22a2 and Slc22a3) } \\
\text { in cis }\end{array}$ & $(30)$ \\
\hline GTL2 (also called MEG3) & $\begin{array}{l}\text { Gene-trap locus } 2 \text { (maternally expressed im- } \\
\text { printed gene 3), had two major mRNA forms }\end{array}$ & $\begin{array}{l}\text { Interacts with the tumor suppressor p53, and } \\
\text { regulates p53 target gene expression }\end{array}$ & $(30)$ \\
\hline
\end{tabular}


Table 2. The Summarized Information of lncRNAs and Related RBPS

\begin{tabular}{lcrc}
\hline LncRNAgene symbol & RNA-binding proteins (RBP) & Target Location & Target Transcripts (Ensembl IDs) \\
\hline HOTTIP & PTB- eIF4AIII- DGCR8- FUS- UPF1 & Chromosome 7 & ENST00000472494 ENST00000605136 \\
& interaction with the WDR5 / MLL complex & ENST00000521028 ENST00000472494 \\
H19 & PTB, eIF4AIII, DGCR8, FUS & Chromosome 11 & ENST00000414790 ENST00000412788 \\
& & ENST00000439725 ENST00000411861 \\
& & ENST00000442037 ENST00000422826 \\
& & ENST00000446406 ENST00000417089 \\
& & ENST00000431095 ENST00000411754
\end{tabular}

\begin{tabular}{|c|c|c|c|}
\hline uco02mb & Un-predictable & & \\
\hline \multirow[t]{2}{*}{ HOTAIR } & $\begin{array}{l}\text { HuR, IGF2BP1, IGF2BP2, IGF2BP3, PUM2, } \\
\text { eIF4AIII, FMRP, FUS, LIN28A, LIN28B, } \\
\text { C22ORF28, ZC3H7B, U2AF65, hnRNPC, }\end{array}$ & Chromosome 12 & $\begin{array}{c}\text { ENST00000424518 ENST00000455246 } \\
\text { ENST00000425595 ENST00000453875 } \\
\text { ENST00000439545 }\end{array}$ \\
\hline & UPF1, HuR & & \\
\hline MALAT1 & $\begin{array}{l}\text { PTB, IGF2BP1, IGF2BP2, IGF2BP3, PUM2, } \\
\text { QKI, TNRC6, eIF4AIII, DGCR8, FMRP, FUS, } \\
\text { LIN28A, LIN28B, LIN28, MOV10, ALKBH5, } \\
\text { C17ORF85,C22ORF28, CAPRIN1, ZC3H7B }\end{array}$ & Chromosome 11 & $\begin{array}{c}\text { ENST00000534336 ENST00000544868 } \\
\text { ENST00000508832 }\end{array}$ \\
\hline antisense Igf2r (AIR) & Un-predictable & & \\
\hline GTL2 (also called MEG3) & PTB, eIF4AIII, DGCR8, FUS & Chromosome 14 & $\begin{array}{r}\text { ENST00000429159 ENST00000451743 } \\
\text { ENST00000556736 ENST00000521404 } \\
\text { ENST00000423456 ENST00000398518 } \\
\text { ENST00000554639 ENST00000519709 } \\
\text { ENST00000412736 ENST00000520714 } \\
\text { ENST00000522771 ENST00000424076 } \\
\text { ENST00000452120 ENST00000523671 }\end{array}$ \\
\hline
\end{tabular}

significantly more cell type-specific, Table 1 represents the list of candidate driver IncRNAs in HCC from selected studies. These studies exhibit the expression of lncRNAs HOTTIP, H19, HOTAIR, MALAT1, antisense Igf2r (AIR), HOXA13, GTL2 (also called MEG3) and uc002 mb in HCC. To be aware of the molecular mechanisms of lncRNAs in HCC, it was assumed that lncRNAs are produced to regulate gene expression through their interaction with RBPs, therefore, the binding proteins to IncRNAs needed to be identified. Notably, RNA-binding proteins are the key factors in the regulation of gene expression $(15,16)$.

The next generation sequencing techniques, RNA immunoprecipitation and deletion mapping, quantitative real-time PCR and DNA microarray were the used methods in literature for the identification and potential function assessment of cancer-related IncRNAs. However, predicting RNA target proteins has been a topic of active research. Calculating the sequence similarity average between transcripts and their putative target protein sequences are the base of predicting tools. StarBase is the first database that provides the RNA-protein interaction networks to identify the most popular RBPs. Table 2 revealed predicted human RNA-binding proteins that interact with HCC-related IncRNAs. H19 was one of the first known and most studied IncRNAs, which has indispensable role for regulating of development and disease disorders (19-21). The regulatory function of H19 on the growth through the control of insulin-like growth factor II (IGF2) expression were evaluated by Ripoche et al. that showed the overgrowth phenotype in H19 silencing cells (31). IGF2 and H19 are two imprinted genes in humans with expression of the maternal H19 and paternal IGF2 alleles that are neighboring positioned at chromosome 11p15.5 (32). High expression of IncRNA H19 and its association with cell growth in the development of HCC has been well documented (20). However the biological function and regulatory mechanism of this conserved RNA remain largely unknown. H19 organized a complex of PCAF with acetyltransferase function and RNAPol II to activate miR-200 for higher acetylation of histones as important process in transcription (21). However, we anticipated that H19 interact with PTB, eIF4AIII, DGCR8 and FUS regulatory binding proteins (Table 2). The IncRNA HULC, promoted cell proliferation and involved in HBx-mediated hepatocarcinogenesis by the use of cAMP-responsive element-binding protein (28). However there were no anticipated RBPs for HULC in the databases. The IncRNA HOTAIR is a new potential marker of $\operatorname{HCC}(15,25,26)$. Analysis of microarray gene expression data showed the increased level of HOTAIR in HBV related HCC compare to normal liver tissues. Microarray expression analysis showed that high expression level of HOTAIR was an independent predictive for shorter recurrence-free survival of HCC after liver transplantation (27). Indeed, the marked up-regulation of IncRNAs MALAT1 and HOTTIP in HCV and HBV-associated HCC have been described $(33,34)$. MALAT1 with $8.7-\mathrm{kb}$ in length has been associated with metastasis and poor prognosis of HCC according to histology find- 
ings. It is famous as an oncogene, because it regulates alternative splicing of endogenous target genes that are involved in cancer (29). HOTTIP(the transcript of HOXA at the distal tip with $3.8 \mathrm{~kb}$ ) directly controls the HOXA locus gene expression via interaction with the complex of transcription factors WDR5 and MLL histone methyltransferase protein. Hox genes have regulatory functions to control the timing and route of development. Deregulation of Hox genes are involved in hepatocarcinogenesis $(7,35)$. Notably, researchers have demonstrated that down regulation of HOTAIR, MALAT1 and HOTTIP can reduce cell viability and cell invasion in tumoral cells, but rise TNF- $\alpha$ induced apoptosis $(10,27,29)$. This study anticipated that eIF4AIII, PTB and FUS were the most implicated RBPs in interaction with HCC related lncRNAs. Eukaryotic initiation factor 4A-III (eIF4AIII) is a member of Define DEAD box proteins, a group of proteins that are implicated in regulation of a range of metabolic processes through interaction with RNA or other nucleic acids. Indeed polypyrimidine tract-binding protein, PTB or hnRNPI is known as a splicing regulator with functional role in mRNA stability and localization. Also RNA-binding protein FUS (fused in sarcoma) is unique and famous for protein regulatory function in transcription and DNA repair activity.

\section{Discussion}

It has been well documented that at least $90 \%$ of the human genome is actively transcribed. Currently, it has been documented that non-protein coding transcripts have regulatory function in cancer biology mainly through their relationships with RNA-binding proteins (RBP) in a sequence-specific manner $(7,15,25,36)$.

These data demonstrated that the interaction of $1 n$ cRNAs with RBPs might effect on the epigenetic regulatory function of IncRNAs molecules in mRNA inactivation and therefore, influence in common cellular functions. Furthermore, RBPs interacting with mRNA for biological function are probably blocked in lncRNAs-RBPs interactions. These finding suggest for oncogenic role of HCCrelated lncRNAs.

Analyses of human genome have revealed prevalent large RNA transcripts that are long non-coding RNAs (lncRNAs). These molecules have regulatory impact on gene expression in interaction with human genome and RNAs. LncRNAs are also organized in close relationship with RBPs regulatory proteins that suggest the importance of regulatory binding proteins in biological role of lncRNAs. The present study has been focused on well-defined lncRNAs in HCC and their interaction with regulatory proteins. H19, HOTAIR, MALAT1 and HOTTIP are most common lncRNAs in HCC. These lncRNAs are essential in many biological events for instance cell-proliferation and differentiation, apoptosis and tumorigenesis via their impact on RBPs. A few approaches are available for predicting interactions between IncRNAs and proteins. Here, the StarBase database showed that eIF4AIII, PTB and
FUS were the most implicated RBPs in interaction with HCC related lncRNAs. Engagements of these RBPs by lncRNAs probably explain the tumorigenicity in HCC and opens new opportunities for novel therapeutic targets in HCC.

\section{Acknowledgements}

This study was supported by Liver and Pancreatobiliary Disease Research Center, Digestive Disease Research institute, Tehran University of Medical Sciences, Tehran, Iran.

\section{References}

1. Carninci P, Kasukawa T, Katayama S, Gough J, Frith MC, Maeda N et al. The transcriptional landscape of the mammalian genome. Science. 2005;309(5740):1559-63.

2. Ponting CP, Oliver PL, Reik W. Evolution and functions of long noncoding RNAs. Cell. 2009;136(4):629-41.

3. Mercer TR, Mattick JS. Structure and function of long noncoding RNAs in epigenetic regulation. Nat Struct Mol Biol.2013;20(3):300-7.

4. Qiu MT, Hu JW, Yin R, Xu L. Long noncoding RNA: an emerging paradigm of cancer research. Tumour Biol. 2013;34(2):613-20.

5. Du Z, Fei T, Verhaak RG, Su Z, Zhang Y, Brown M, et al. Integrative genomic analyses reveal clinically relevant long noncoding RNAs in human cancer. Nat Struct Mol Biol. 2013;20(7):908-13.

6. Enfield KS, Pikor LA, Martinez VD, Lam WL. Mechanistic Roles of Noncoding RNAs in Lung Cancer Biology and Their Clinical Implications. Genet Res Int. 2012;2012:737416.

7. Quagliata L, Matter MS, Piscuoglio S, Arabi L, Ruiz C, Procino A, et al. IncRNA HOTTIP / HOXA13 expression is associated with disease progression and predicts outcome in hepatocellular carcinoma patients. Hepatology. 2013.

8. Xie H, Ma H, Zhou D. Plasma HULC as a promising novel biomarker for the detection of hepatocellular carcinoma. Biomed Res Int. 2013;2013:136106.

9. He Y, Meng XM, Huang C, Wu BM, Zhang L, Lv XW, et al. Long noncoding RNAs: Novel insights into hepatocelluar carcinoma. Cancer Lett. 2013.

10. Pan YF, Qin T, Feng L, Yu ZJ. Expression profile of altered long noncoding RNAs in patients with HBV-associated hepatocellular carcinoma. J Huazhong Univ Sci Technolog Med Sci. 2013;33(1):96-101.

11. Yeganeh B, Hashemi M, de Serres FJ, Los MJ, Ghavami S. Different faces of hepatocellular carcinoma as a health threat in 21st century. Hepat Mon. 2013;13(2).

12. Zidan A, Scheuerlein H, Schule S, Settmacher U, Rauchfuss F. Epidemiological pattern of hepatitis $B$ and hepatitis $C$ as etiological agents for hepatocellular carcinoma in iran and worldwide. Hepat Mon. 2012;12(10 HCC).

13. Mohamadkhani A, Montazeri G, Poustchi H. The Importance of Hepatitis B Virus Genome Diversity in Basal Core Promoter Region. Middle East Journal of Dig Dis. 2011;3:13-9.

14. Alswat KA, Sanai FM, Altuwaijri M, Albenmousa A, Almadi M, AlHamoudi WK, et al. Clinical characteristics of patients with hepatocellular carcinoma in a middle eastern population. Hepat Mon. 2013;13(5).

15. Gupta RA, Shah N, Wang KC, Kim J, Horlings HM, Wong DJ, et al Long non-coding RNA HOTAIR reprograms chromatin state to promote cancer metastasis. Nature. 2010;464(7291):1071-6.

16. Semrad K. Proteins with RNA chaperone activity: a world of diverse proteins with a common task-impediment of RNA misfolding. Biochem Res Int. 2011;2011:532908.

17. Li JH, Liu S, Zhou H, Qu LH, Yang JH. starBase v2.0: decoding miRNA-ceRNA, miRNA-ncRNA and protein-RNA interaction networks from large-scale CLIP-Seq data. Nucleic Acids Res. 2014;42(1):D92-7.

18. Amaral PP, Clark MB, Gascoigne DK, Dinger ME, Mattick JS. lncRNAdb: a reference database for long noncoding RNAs. Nucleic Acids Res. 2011;39(Database issue):D146-51.

19. Kim KS, Lee YI. Biallelic expression of the H19 and IGF2 genes in 
hepatocellular carcinoma. Cancer Lett. 1997;119(2):143-8.

20. Sohda T, Iwata K, Soejima H, Kamimura S, Shijo H, Yun K. In situ detection of insulin-like growth factor II (IGF2) and H19 gene expression in hepatocellular carcinoma. J Hum Genet. 1998;43(1):49-53.

21. Zhang L, Yang F, Yuan JH, Yuan SX, Zhou WP, Huo XS, et al. Epigenetic activation of the MiR-200 family contributes to H19mediated metastasis suppression in hepatocellular carcinoma. Carcinogenesis. 2013;34(3):577-86.

22. Wu J, Qin Y, Li B, He WZ, Sun ZL. Hypomethylated and hypermethylated profiles of H19DMR are associated with the aberrant imprinting of IGF2 and H19 in human hepatocellular carcinoma. Genomics. 2008;91(5):443-50.

23. Morford LA, Davis C, Jin L, Dobierzewska A, Peterson ML, Spear BT. The oncofetal gene glypican 3 is regulated in the postnatal liver by zinc fingers and homeoboxes 2 and in the regenerating liver by alpha-fetoprotein regulator 2. Hepatology. 2007;46(5):1541-7.

24. Iizuka N, Oka M, Tamesa T, Hamamoto Y, Yamada-Okabe H. Imbalance in expression levels of insulin-like growth factor 2 and H19 transcripts linked to progression of hepatocellular carcinoma. Anticancer Res. 2004;24(6):4085-9.

25. Ishibashi M, Kogo R, Shibata K, Sawada G, Takahashi Y, Kurashige J, et al. Clinical significance of the expression of long non-coding RNA HOTAIR in primary hepatocellular carcinoma. Oncol Rep. 2013;29(3):946-50.

26. Geng YJ, Xie SL, Li Q, Ma J, Wang GY. Large intervening non-coding RNA HOTAIR is associated with hepatocellular carcinoma progression. J Int Med Res. 2011;39(6):2119-28.

27. Yang Z, Zhou L, Wu LM, Lai MC, Xie HY, Zhang F, et al. Overexpression of long non-coding RNA HOTAIR predicts tumor recurrence in hepatocellular carcinoma patients following liver transplantation. Ann Surg Oncol. 2011;18(5):1243-50.
28. Du Y, Kong G, You X, Zhang S, Zhang T, Gao Y, et al. Elevation of highly up-regulated in liver cancer (HULC) by hepatitis B virus X protein promotes hepatoma cell proliferation via down-regulating p18. J Biol Chem. 2012;287(31):26302-11.

29. Lai MC, Yang Z, Zhou L, Zhu QQ, Xie HY, Zhang F, et al. Long noncoding RNA MALAT-1 overexpression predicts tumor recurrence of hepatocellular carcinoma after liver transplantation. Med Oncol.2012;29(3):1810-6.

30. Oliva J, Bardag-Gorce F, French BA, Li J, French SW. The regulation of non-coding RNA expression in the liver of mice fed DDC. Exp Mol Pathol. 2009;87(1):12-9.

31. Ripoche MA, Kress C, Poirier F, Dandolo L. Deletion of the H19 transcription unit reveals the existence of a putative imprinting control element. Genes Dev.1997;11(12):1596-604.

32. Teschke K, Kelly SJ, Wiens M, Hertzman C, Dimich-Ward H, Ward JE, et al. Concentrations of organochlorine pesticides in the adipose tissue of British Columbia residents. Can J Public Health. 1993;84(3):192-6.

33. Yang F, Zhang L, Huo XS, Yuan JH, Xu D, Yuan SX, et al. Long noncoding RNA high expression in hepatocellular carcinoma facilitates tumor growth through enhancer of zeste homolog 2 in humans. Hepatology. 2011;54(5):1679-89.

34. Hou W, Bonkovsky HL. Non-coding RNAs in hepatitis C-induced hepatocellular carcinoma: Dysregulation and implications for early detection, diagnosis and therapy. World J Gastroenterol. 2013;19(44):7836-45.

35. Wang KC, Yang YW, Liu B, Sanyal A, Corces-Zimmerman R, Chen $\mathrm{Y}$, et al. A long noncoding RNA maintains active chromatin to coordinate homeotic gene expression. Nature. 2011;472(7341):120-4.

36. Brannan K, Bentley DL. Control of Transcriptional Elongation by RNAPolymerase II:A Retrospective. Genet Res Int.2012;2012:170173. 